\title{
Microclimate Factors for Sustenance and Optimum Crop Production in Greenhouse System
}

\author{
${ }^{1}$ Akinyoola, J.A, ${ }^{1}$ Ologunagba, F.O. and ${ }^{2}$ Omonijo, G. \\ ${ }^{I}$ (Agricultural Engineering Technology Department, Rufus Giwa Polytechnic, P.M.B 1019, Owo, Nigeria) \\ ${ }_{2}^{2}$ (Agricultural Technology Department, Rufus Giwa Polytechnic, P.M.B 1019, Owo, Nigeria)
}

\begin{abstract}
Greenhouse system is an alternative to economic problems faced as a result of climate variability which has so far hindered agricultural practices, hydropower, hydrological cycle and drought relieve. The survey covers green house system and management within humid tropical area of Nigeria. The study includes crops of different types such as Cucumber and Sweet Melon. It cover within the period of sowing (nursery), transplanting and harvesting. The result revealed that the necessary microclimate factors such as Temperature of $28^{\circ} \mathrm{C}$ and Relative Humidity of $85 \%$ are necessary for the maximum growth, development and productivity of these crops. Higher temperature aids flowering and support photoperiodism. Crops suffer low quality output and invasion of pests and diseases when humidity threshold is at minima.
\end{abstract}

Keywords: Green house, nursery, transplanting, harvesting and photoperiodic

\section{Introduction}

Climate is referred to as a statistical weather condition over a place say $30-50$ years $[1,2,3]$.

But in reality, climate can be regarded as the characteristics condition of the atmosphere near the earth surface at a given place or over a given region since it is always changing in time and space. On the other hand, weather is a state or condition of atmosphere at a given place and at a given time. It is a variations or conditions of lower layer of the atmosphere. Weather pattern of smaller areas like villages and districts are expressed by numerical values of meteorological parameters such as solar radiation, air temperature, atmospheric pressure, wind speed, relative humidity, precipitation and clouds.

Solar energy is the main factors influencing temperature and thus varies from one place to another. The principal heating of air during the day is produced by its contact with a land surface that has been heated by the Sun's radiation. Heat from the ground is transferred to the air by conduction and convection.

Greenhouse System is primarily built for temperature control purposes, which also influence other meteorological elements. Ordinary glass transmits short wave radiation, but absorbs the long wave "heat" radiation from terrestrial sources (green house effect). However, heat is conducted through the glass and is dissipated from the outer surface partly by radiation and partly by convection. Compare with metals, glass is a poor conductor, but it conduct better than many insulating and building materials. In the absence of convective exchange, heat is retained and the amount stored increases above that which occurs in the open. [4]

If these results are interpreted in terms of their effect on the time of commencement of the growing season, a gain of three to four weeks is indicated. Such gain in temperature may be advised in early season, during germination and emergence of crop when the soil is effectively bare. It must be emphasized that the presence of a vegetable like cucumber and sweet melon will reduce the temperature difference, due partly to the shading of the ground and partly to the heat required for transpiration. A general consideration of soil temperature variations reveals that the heat transport in the soil of the green house and that in the open are similar. However, for all depths, the green house soil is significantly warmer than that in the open. More importantly, low relative humidity can be obtained in the green house in practice either by increasing the air temperature or by ventilation. High relative humidity can also be obtained by increasing evaporation from the soil into the green house with relatively low air temperature.

Solar energy provides the sunlight required for seed germination, leaf expansion, growth of stem and shoot, flowering, fruiting and thermal conditions necessary for the physiological functions of the plant. [5] More than 70 percent of the solar radiation absorbed by plant is converted into heat. This heat energy is utilized for transpiration and convective heat exchange with the surrounding. This exchange determined the temperature of leaves and other plants parts.

\subsection{Effect of Temperature and Photoperiodism}

The photoperiodic effect is realized only when optimum temperature prevails. Even in photosensitive variety. Flowering is not induced when the temperature is extremely low. However, within the normal range, temperature advances or hastens flowering. Also, Relative lengths of day and night not only influence flowering 
but also affect other processes like initiation of leaves and fruits. Number of leaves produced is less with decrease and increase in photoperiodism with short and long day plants respectively. Leaf number increases with increase in temperature. However, Relative humidity (RH) directly influences the water relations of plant and indirectly affects leaves growth, photosynthesis pollination, occurrence of diseases and pest and final economic yield. The dryness of atmosphere as represented by saturation deficit (100-RH) reduces dry matter production through stomata control and leaf water potential.

Relative humidity have a considerable influence on evapotranspiration and water requirement for crops. At constant temperature, changes in atmospheric humidity affect transpiration by modifying the vapour pressure gradient from leaf to air at different stages of crop, especially during vegetative phase.

\subsection{Objective of the Study}

(a) to create higher ambient and soil temperature, in order to reduce the risk of low temperature which enhance the control of soil moisture and humidity.

(b). to determine the extent to which micro-climatic elements influence green house system in South-western area of Nigeria.

(c) to identify the major constraint affecting green house system.

\section{Methodology}

About 400 to 500 litre of water is necessary for the production of a kilogram of plant dry matter. Water is also required for translocation of nutrients and dissipation of heat, Irrigation however, is the artificial application of water to soil to supplement rainfall for crop production. Irrigation provides favourable environment for higher crop growth and yield.

There are various types of irrigation systems which includes sprinkler, drip irrigation, centre pivot and so on. In this study more emphasis is laid on drip irrigation system being the best method adopted in this research. Drip irrigation is the precise slow application of water in the form of discrete or continuous or tiny streams covertures spray through mechanical devices called emitters or application located at selected points along water delivery pipes [6]. The term trickle or drip irrigation are used.

In 1964 the first patented drip irrigation system was developed and established by Richard Chapin in the late sixties. This concept spread to Australia and USA. And eventually to several countries in the world. Drip irrigation is adopted extensively in green house system and especially for crops such as cucumber, sweet melon, tomato, green pepper, Lettuce and so on. Drip irrigation system consist of the following components:

i. Pump to lift the water from the source of supply.

ii. A head unit consisting of a tank to maintain the required pressure for circulation of water.

iii. A central distribution system connected to main water supply, which regulates water pressure and quantity

iv. A filter, connected to the central distribution system, to remove materials suspended in water.

v. PVC main supply pipe of suitable diameter and length to deliver the desired discharge.

vi. Sub - main or laterals of suitable diameter and length connected in a parallel way to the main and

vii. Plastic dripper inserted in the lateral at the desire spacing (equal to the intra - row spacing of the plant) which control the release of the desired quantity of water.

Other types of drip irrigations includes: sub surface drip irrigation system where laterals are buried below the soil surface and pulse irrigation system supplies water in series of pulse or discharge at an interval of five, ten and fifteen minutes.

\subsection{Analysis of Drip Irrigation Design for Green House System}

Number of plants (Cucumber) $\equiv$ Area Spacing

$$
\begin{aligned}
& =30 \mathrm{cmX} 30 \mathrm{~cm} \\
& =0.30 \mathrm{~m} \\
& \equiv 35 \text { plants }
\end{aligned}
$$

Evaporation of crop can be estimated by pan evaporation method.

$E t_{0}-E_{p} * K_{p}$

Where $E t_{0}$ is the Reference evapotranspiration or potential evapotranspiration in millimeter(mm).

$E_{p}$ is the pan evaporation in millimeter per day (mm/day) and

$K_{p}$ is the pan coefficient

This estimation is limited due to lack of instruction to plant in place.

a) Drip irrigation has proved to be a success in terms of water and increase yield in a wide range of crops

b) Increase in yield range from $20 \%$ to as high as $100 \%$. 
c) The saving in water depends on crops, soil and environmental conditions. The main reasons for saving of water are absence of conveyance and run off losses, reduced evaporation due to minimum or no deep percolation. Drip irrigation provides opportunity for enhance plant growth and yield.

Drip irrigation provides sufficient amount of water throughout the growing season unlike other methods where soil moisture fluctuates from field capacity to different degree of dryness between irrigation. Drip irrigation reduced salinity hazard to plants due to low salt concentration owing to high availability of water continuously.

Weed infestation is less with drip irrigation because only small area is wetted.

\subsection{Fertigation method}

Fertilizers are industrially manufactured chemicals containing plant nutrients. Nutrients content is higher in fertilizers than in organic manure, and nutrients are released immediately [8]. Straight fertilizer, are those which supply only one primary plant nutrient, namely Nitrogen, Phosphorus and Potassium (NPK) which is majorly used for cucumber and sweet melon. Mixed fertilizers are physical mixture of straight fertilizer, they contains two or three primary plant nutrients.

The physical form of fertilizers are in several forms: powder (single super phosphate crystals (ammonium phosphate), pill ( Urea, Diammonium phosphate, super phosphate), granulated ( Urea Super granule). Other fertilizers are in liquid form for applying with irrigation water or for direct application

There are various methods of fertilizer application which includes broadcasting, broadcasting and incorporation, band placement, point placement, sub soil placement, fertigation, root dipping and foliar spray. Equal proportion of fertilizer and accurate amount of water and its application is known as fertigation. It is generally followed with drip irrigation as used in green house system, depth with the help of hand hoes in which weed are uprooted and removed.

\subsection{Phonological Observation on Developmental Phases of Cucumber and Sweet Melon.}

Table 1. Phonological Observation Table

\begin{tabular}{|l|l|l|l|}
\hline Week & $\begin{array}{l}\text { Sweet } \\
\text { Mellon }\end{array}$ & Cucumber & Observation \\
\hline Week I & 3 leaves & 2 leaves & $\begin{array}{l}\text { Shooting and leave initiation was } \\
\text { faster in sweet mellon }\end{array}$ \\
\hline Week II & 5 leaves & 4 leaves & Transplanting performed. \\
\hline Week III & 7 leaves & 7 leaves & First Fumigation performed \\
\hline Week IV & 10 leaves & 9 leaves & Weeding performed \\
\hline Week V & $\begin{array}{l}\text { 6 Flowers } \\
\text { Observed }\end{array}$ & $\begin{array}{l}\text { Shoot } \\
\text { elongation } \\
\text { and flowering }\end{array}$ & $\begin{array}{l}\text { Flowering rate is higher in Sweet } \\
\text { Mellon }\end{array}$ \\
\hline Week VI & Fruiting & Fruiting & $50 \%$ Flowering \\
\hline Week VII & Fruiting & Fruiting & $100 \%$ flowering on Sweet Mellon \\
\hline Week VIII & $\begin{array}{l}\text { Mature } \\
\text { Fruits }\end{array}$ & First Harvest & $\begin{array}{l}\text { Second Fumigation and Weeding } \\
\text { performed }\end{array}$ \\
\hline Week IX & $\begin{array}{l}\text { First } \\
\text { Harvesting }\end{array}$ & $\begin{array}{l}\text { Second } \\
\text { Harvesting }\end{array}$ & Harvesting \\
\hline
\end{tabular}

\subsection{Rate of Flowering}

This parameter indicates whether most of the branches flower in quick succession or not. In other words, it indicates synchronous flowering. It is expressed as number of flowers that appears per day.

Flowering Rate $(f r)=\frac{f r_{2}-f r_{1}}{T_{2}-T_{1}}$

Where $f r_{2}$ and $f r_{1}$ are the number of flowers that appear per day.

Flowering rate for sweet melon.

$f r_{2}=3$

$f r_{1}=1$

$T_{1}=900 \mathrm{z}$

$T_{2}=1800 \mathrm{z}$ 


$\begin{aligned} f r= & \frac{3-1}{1800-900} \\ & =2 / 9 \\ & =\mathbf{0 . 2}\end{aligned}$

This indicates the number of days in which $50 \%$ of the plants flowers.

When more than one crop is to be grown in a year on the same piece of land, the time occupied by each crop has to be reduced. The seedling growth in the early stages is very slow. Seedlings need extra care for establishing in the field because of their tenderness. Small seeded crops like green pepper, cucumber and sweet melon are to be sown shallow and frequently irrigated for proper germination and development. Taking care of the germinating seed or seedlings, which are spread over a large area, is a problem with regard to application of water, weed control, pest control and so on. Therefore, seeds are sown in a small area called nursery and all the care is taken to raise the seedlings. When they grown to certain stage, they are pulled out from the nursery and transplanted in the main field. The advantages of transplanting are good stand establishment and increase intensity of cropping.

To achieve good results from transplanting, the seedlings are transplanted at optimum age and at proper depth. The optimum time of transplanting cucumber and sweet melon from nursery is thirteen days interval and at a depth of five centimeters $(5 \mathrm{~cm})$ to the ground. Emerged seedling becomes independent when the third leaf has fully expanded and the forth leaf just appears. However, early nursery during certain period increases the yield. An optimum temperature is very necessary thereby increase yields due to suitable environment at all the growth stages of the crop. Table 1 shows the nursery of cucumber and sweet melon.

\subsection{Criteria for harvesting}

In cucumber, harvesting is 19 days after flowering when fruit has increased in size and thicken in the outer wall, while in sweet melon it is 30 days after flowering. Harvesting generally occurs several days after physiological maturity and the important processes during this period is loss of moisture from the plants. This maturity index is a good indicator for deciding the time for harvesting.[9]

The data used are primary data collected on daily bases in side the green house from January to July which also includes the period of planting of cucumber and sweet melon from nursery to harvesting time. Primarily, data are very useful in this purpose as it is widely used to find the averaged temperature per day or monthly mean temperature and to compute monthly mean of relative humidity within the threshold which is attainable and sustainable for crop production and weather forecasting for proper farm management and pest diseases.

Table 2. Monthly variation of Temperature and Relative Humidity

\begin{tabular}{|l|c|c|c|c|c|c|c|}
\hline & Jan & Feb & Mar. & April & May & Jun & Jul \\
\hline Mean Monthly Temp $\left({ }^{\circ} \mathrm{C}\right)$ & 28 & 29 & 30 & 29 & 29 & 25 & 26 \\
\hline Mean Monthly R.H (\%) & 85 & 84 & 84 & 83 & 85 & 88 & 86 \\
\hline
\end{tabular}

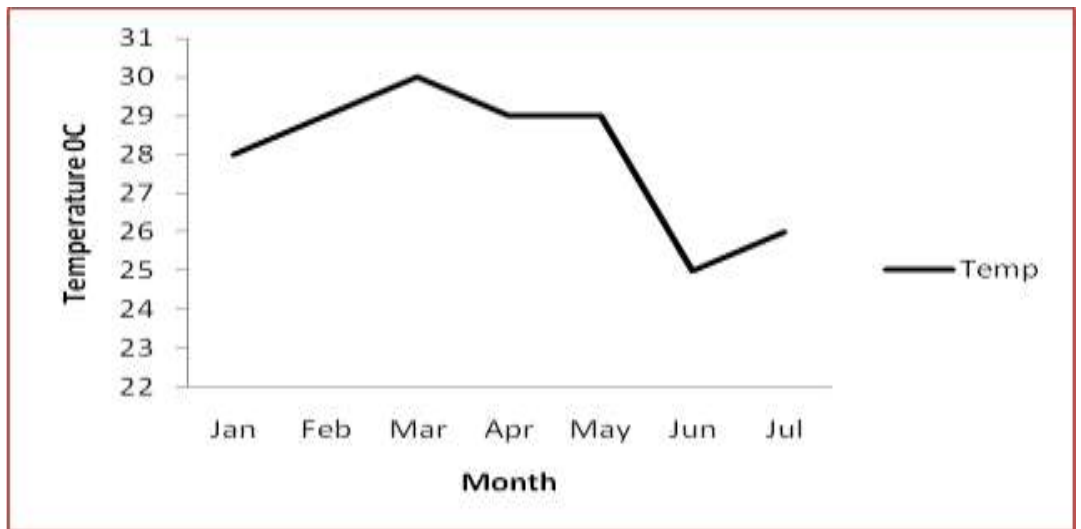

Figure 1. Monthly Variation of Temperature 


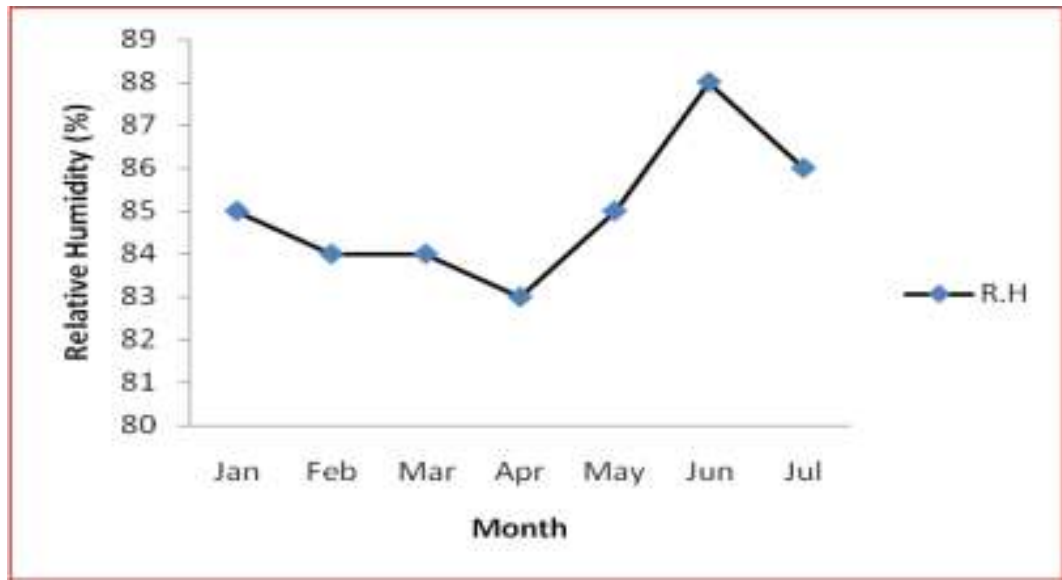

Figure 2. Monthly Variation of Relative Humidity

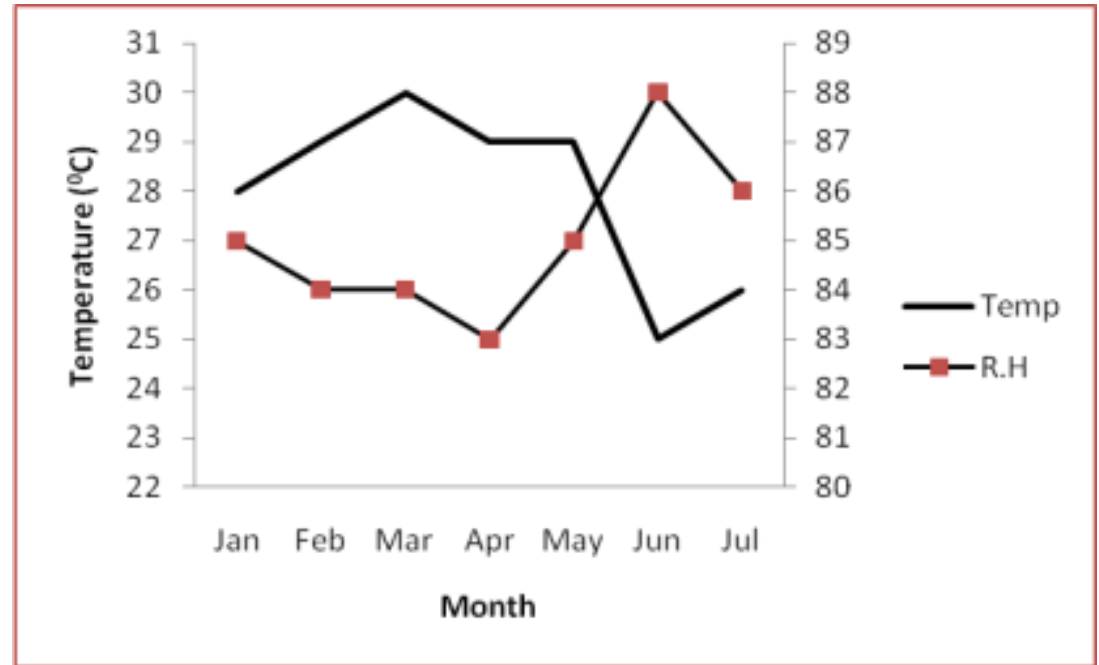

Figure 3. Monthly Variation of Temperature with Relative Humidity

From Figure1, temperature of $30^{\circ} \mathrm{C}$ was recorded in March and this shows a drastic decrease in relative humidity of $84 \%$ as shown in Figure2. Likewise, in April, the average temperature amount to $29^{\circ} \mathrm{C}$ and this recorded the least relative humidity of $83 \%$. Conversely, highest average relative humidity of $88 \%$ was recorded in June when the temperature was amounts $25^{\circ} \mathrm{C}$, that is, at this period both variables are in place. By the end of June the temperature increases gradually while relative humidity decreases as July approaches.

Figure 3 shows variation of relative humidity with temperature. It was clearly shown that relative humidity decreases drastically with increase in temperature until the temperature was at $30^{\circ} \mathrm{C}$.

\section{Result/Discussion}

Comparing the phonological observation on the various phases of crop growth and development and management with graphical analysis. The following deductions were made:

(a) In May, the average temperature was $29^{\circ} \mathrm{C}$ with relative humidity of $85 \%$. It was observed that normal growth and development were recorded on both crops and at the $13^{\text {th }}$ day, nursery transplanting was done. This shows the condition of temperature and relative humidity for both crops.

(b) In June for instance when both temperature and relative humidity were in phase, outbreak of pests and diseases were noticed. This is as a result of high amount of relative humidity $(88 \%)$ recorded. Therefore, the first fumigation had to be carried out to prevent destruction or attack that might be done on the crops. Host and pest multiply at rates that depends on temperature also, as temperature rises, growth and reproduction of the pest increases, until the weather becomes too hot, at which time they slow down and finally stop.

(c) Rate of flowing continues on both crops but much more significant on sweet melon to cucumber. Up to $100 \%$ flowering was recorded by the seventh week at the expense of high mean temperature value.

(d) As noted, temperature aids flowering 'rate as shown clearly by the $100 \%$ rate of flowering on both crops. 
(e) Harvest of fruits was done on both crops by the ninth week. Subsequent fruiting increases per area covered which increased the gross weight of harvestings.

(f) Optimum temperature about $28^{\circ} \mathrm{C}$ is therefore necessary for both sweet melon and cucumber for an efficient growth, development and fruiting. Also, Relative humidity below $85 \%$ is appropriate for efficient growth and development of both crops.

\section{Conclusion}

Green house does not prevent heat from been lost through radiation. They do however reduce heat lost through convection by eliminating wind turbulent and the effect felt particularly during daytime, as such greatly reduced water loss from the crop. At night, they probably buffer the crop from the drastic temperature drop by the absence of heat loss due to wind flow. It also creates an air layer saturated with water, thereby providing a higher heat-capacity environment and a layer of insulation for long-wave radiation loss. Green house therefore allows the supply of produce to the market at an early date. An optimum temperature should be maintained inside the green house so as to avoid any unfavourable condition that might hinder the growth and development of the crops. However, when RH is exactly $85 \%$, fumigation operation must be carried out so as to prevent damages from pests and diseases attack.

\section{References}

[1] Flohn, H. 1999. Climate and Weather. World Univ. Library. McGraw-Hill, New York. 1969

[2] Royal Meteorological Society weather. November, 1989. Volume 44, Issue 11, pp $449-450$

[3] Jose, L., Hupfer, P. and Nortgra J.B.Journal, Climate of the 21" century.1975, pp 194-196.

[4] Searle, S.A. and Smith, L.P. Weatherwise gardening Book. 1958. Pp 246

[5] Shoals,M., Rosenberg, N.J. Adaptation of agriculture to climate change. Climinate Change1992. 21:385-405

[6] Charles, M.B. and Stuart, W.S. Drip and Micro Irrigation Design and Management for trees, vines and field crops. 2007

[7] FAO. Crop Evapotranspiration- Guidelines for computing crop water requirements. FAO corporate document respository. 1998.

[8] Stewart, W.M., Dibb, D.W., Johnston, A.E., Smith, J.J. The Contribution of Commercial Fertilizer Nutrients to Food production. Agronomy journal . 2005, 97: 1-6.

[9] Yellamanda, R.T. and Sankara, G.H. Principle of Agronomy, Kalyani Publishers, Ludhiana, India. 1992 